\title{
Prevention of extremism in the modern youth environment
}

\author{
Alexey Antoshin ${ }^{1, *}$, Valery Antoshin ${ }^{2}$ \\ ${ }^{1}$ Ural Federal University, Yekaterinburg, Russia \\ ${ }^{2}$ Ural Institute of Management of the Russian Presidential Academy of National Economy and Public \\ Administration Professor of the Regional and Municipal Management Department, Yekaterinburg, \\ Russia
}

\begin{abstract}
The problem of countering extremism is one of the key areas in the framework of national policy aimed at ensuring the national security of Russia The report analyzes the problem of preventing extremist sentiments among modern Russian youth. The statutory legal regulations adopted in the Russian Federation on combating extremism, as well as the Russian experts' proceedings on this issue formed the theoretical basis of the study. The authors prove that the methodological basis for the prevention of extremist sentiments among young people existing in our country needs further development and improvement.
\end{abstract}

\section{Introduction}

The problem of countering extremism is one of the key areas in the framework of national policy aimed at ensuring the national security of Russia. It is no coincidence that our country has created an extensive regulatory framework for combating extremism and terrorism [7, 11-22]. Among the primary documents devoted to this problem, the Federal Law of July 25, 2002 "On countering extremist activity" should be highlighted.

It is exactly in this law the priority of measures aimed at preventing extremist activity is defined as the main principle of countering extremism. At the legislative level in the Russian Federation, attention is paid to the prevention of extremist activity. In this case, particular emphasis is made on the interaction of public bodies, local self-government bodies with civil society institutions. In this case, we are talking about confessions, national and cultural associations, as well as other public associations. I would like to draw attention to the current Strategy of countering extremism in the Russian Federation until 2025. It is in this document that the priority of preventive measures in relation to criminal law methods is conceptually fixed.

In our opinion, preventive work is aimed at implementing measures to form antiterrorist consciousness among citizens of the Russian Federation.

As you know, law enforcement agencies deal, as a rule, with an already accomplished fact of an extremist crime, as well as with a bearer of extremist socio-psychological attitudes.

\footnotetext{
*Corresponding author: alex_antoshin@mail.ru
} 


\section{Material and methods}

The key role, in our opinion, in preventing extremism is played by the joint efforts of public authorities, local self-government bodies and civil society institutions.

It must be borne in mind the fact that interethnic (interfaith) and other conflicts arise within the region, when it is necessary to respond to actions or statements that do not fall under criminal or administrative responsibility. In this case, a special role is assigned to preventive measures.

In some regions of Russia (for example, in the Rostov Region), regional national programs have been developed that specify federal measures.

Particular attention is paid to the prevention of extremism among young people. It is no coincidence that the Board of the Ministry of Education and Science at its meeting on June 18,2013 designated this issue as a priority direction for the development of modern national youth policy. This circumstance is due to the fact that, according to the majority of researchers, it is the youth that is the most vulnerable group for the propaganda of extremist organizations. As pointed out, for example, by A. A. Parshina, N. E. Polyanichko and L. A. Guterman, in the youth environment, "accumulation and implementation of negative protest potential occurs most quickly" [5, 117]. This is due to the psychological characteristics of this group: according to the fair remark of V. L. Nazarov and P. E. Suslonov, "extremity acts as an essential characteristic of youth, which means various forms of manifestation of maximalism in consciousness and extremes in behavior at the group and individual-personal levels" $[4,117]$.

These features of the psychology of youth are especially clearly manifested in critical periods for the country associated with powerful transformational shifts, the process of society modernization. This situation was typical, for example, for the period of the late XIX - early XX centuries, marked by the rapid radicalization of society and the active participation of young people in the activities of extremist political organizations. Similar trends can be seen in modern Russia: according to L. M. Lutsenko and Yu. V. Lutsenko, now our society is "acutely experiencing the transformation of the value system due to the modernization of public life" [3, 238]. The negative consequences of this process most acutely affect young people as one of the vulnerable categories of citizens.

It seems to us quite appropriate to pay attention to the main causes and sources of extremism in our country: the rather abrupt social changes of the early 90s; social contrasts, the stratification of society into poor and rich; the scrapping of the old ethnogeographic structure and the slow development of a new one; unregulated migration.

\section{Results and discussions}

A number of researchers, including A.M. Aripshev, see the reason for the involvement of young people in radical and extremist groups as "misunderstanding of the whole essence and danger of terrorism and extremism, lack of respect for the older generation" [8, 129].

After the collapse of the Soviet Union, our state plunged into the era of reformation, the process of Russian society's entry into the system of the global information space began. Public youth policy, at the moment, is not holistic, and not enough attention is paid to the problem itself. Young people, as the most active part of the population, could not help but react to the changes taking place. The social and psychological peculiarity of the younger generation, its features such as maximalism, overly emotional perception of the surrounding world only strengthen the radicalism potentially inherent in the youth. The resulting vacuum in the work of social institutions of education, young people fill with communication in the Internet space, where existing socio-cultural and economic difficulties are actively heated up. Negative ideas spread to a large percentage of the youth 
audience, which creates risks for young people to be used for the purposes of radical ideology. This issue could be solved by the institutions of family and education, but they themselves are in a state of crisis and do not have a unified system in matters of education. Communication between generations is disrupted, the transfer of moral values from the older generation to the younger. The problem here lies not even in the characteristics of the younger generation, but in the complex state of the entire Russian society. The socioeconomic situation in the country as a whole plays an important role here. The crisis in society, in the economy, is a kind of catalyst for those "sleeping" radical sentiments that are present in any society. Lack of confidence in the future, lack of constant earnings, a sense of their uselessness for society attract young people to places where they are in demand, enjoy authority and feel part of the group. These groups are often criminal or extremist in nature. In these groups with young recruits, powerful indoctrination is carried out, using the already existing unsettled young people and pushing them to extremist and terrorist crimes.

It was in the 90 s that the threat to national security was posed by the processes of regional rule-making, which contradicted federal legislation, disrespectful attitude to human rights and freedoms, a separate nation. All this was encouraged by national elites, stimulated separatist sentiments, and contributed to the formation of extremist organizations.

In our opinion, the problem of the spread of extremist views and ideology is caused, among other things, by an insufficiently thought-out youth policy. Falling under the influence of ideological attitudes, some young people perceive representatives of state bodies not as partners, but as enemies of their identity.

According to the Ministry of Justice, 88 organizations have been registered as extremist in Russia to date. This list has been maintained since 2007. Over the past five years, such organizations have increased by 40 units [12]. Extremist organizations differ in their ideological component. "Depending on the content of the requirements and programs of extremists, there are types of extremism: political, national, religious, social, environmental, anti-globalist, gender, sports, cultural" [11, 117-121].

In our opinion, the most dangerous age of entry into the field of activity of extremist organizations is the age from 14 to 22 years. It is at this time that the young man is concerned about finding his identity, the desire to find his group. It is during this period that the process of searching for the meaning and values of life takes place, an acute sense of justice and self-awareness is formed. This is the psychological side of modern youth.

The social characteristic is no less relevant is. The behavior of young people during this period is not determined by any socio-economic factors (permanent promising work, property, family). Precisely in this regard, young people at this age may find themselves in the position of fringe groups due to the instability of views, and the worldview in general.

As a rule, extremism among young people manifests itself in its most pronounced form - the commission of illegal criminal acts in accordance with their beliefs, which is due to the deformation of consciousness. The risk factor for the destructive consciousness of youth is diffuse identity, as well as identity crisis.

Mass character, a high degree of aggressiveness and unjustified cruelty are features of modern youth extremism. The foundation of youth extremist organizations is the loss of orientation of socio-cultural identity, the high potential of aggressiveness accumulated over the years.

It should also be borne in mind that under certain conditions extremism can turn into terrorism, which means that it is already riots, protests, causing bodily harm, murder.

The reasons for the entry of young people into extremist organizations can be: informational and communicative dissatisfaction, loneliness and an acute sense of incomprehensibility, alcoholism of parents and conflict relations in the family. A serious 
reason is also the blocking of the most necessary needs: lack of positive impressions, lack of money and debts, loss of interest in old friends.

It should also be noted that one of the characteristics of youth extremism is the division into "strangers" and "friends". But this division is significantly different from the division of adults. As Yu. A. Zubok and V.I. Chuprov rightly note: "Subcultural factors play a great role in this. Belonging to one or another subculture is accompanied by opposition to traditional culture, shocking its samples and bearers [9, 38]. "Strangers" can become "enemies" only because they came from another city, have a different nationality, they have a different appearance.

Modern youth associations of extremist orientation can be classified on several grounds. We are impressed by the approach of S.A. Sergeev, who suggests the classification of subculture as the basis of systematization: 1. romantic-escapist informal youth groups (hippies, Indianists, Tolkienologists, bikers); 2. hedonistic and entertainment groups (majors, ravers, rappers, etc.) 3. criminal youth groups (group muggers, lyubers): 4. Anarcho-nihilistic groups (punks, skinheads, extremist subcultures of the "left" and "right" kind). It is these groups that can be called radical, more prone to extremism $[14,96]$.

Skinheads and group muggers are the most dangerous and numerous youth informal organizations among those proposed by us in the list. Skinheads participate in all rallies and protests. It is extremely difficult to work with them, because their worldview has already been sufficiently formed, to instill in them a healthy social lifestyle. Murders, harm to health, thefts and robberies are often committed by this group.

This situation induces special attention of social and public structures to the situation in the youth environment. It is no coincidence that in recent years there have been special methodological manuals dedicated to the prevention of extremism among young people. Thus, some researchers pay special attention to institutions of secondary vocational education - lyceums, technical schools and colleges, where, in their opinion, microcommunities may arise that carry certain threats and dangers for adolescents $[5,118]$. Other experts point out that similar problems are typical for both high school students of secondary schools and university students.

The researchers believe that the religious factor should not be exaggerated as the reason for the spread of extremist sentiments. However, considering national-religious extremism one of the most important concepts of this topic, G. M. Gogiberidze points out, "Young Muscovites easily identify themselves with traditional religious culture, but in fact, they have rather vague ideas about all religions" $[1,53]$. Even V. D. Laza, who studied the situation in the Republic of Dagestan, noted that only $14 \%$ of respondents considered a religious factor to be one of the major factors in the spread of extremist sentiments in the region [2, 45]. Other factors are much more important - high rate unemployment, corruption, low standard of living of the population.

Researchers pay much more attention to such a factor as the spread of extremist ideas in the Internet space. Of course, this phenomenon is becoming more and more significant, and specifically young people who are most exposed to those extremist groups that operate in the digital environment. Experts note that social networks, for example, are playing an increasing role in recruiting new members of various gangs [7,9].

Prevention of extremist activity among young people is the sphere of communication and understanding of people with each other and themselves, the sphere of effective adaptation to the environment and to life in general. Of course, this is the part of science and practice that is related to the prevention of mental health. It can also be argued that this is the practice of social work.

What measures do experts propose as part of the prevention of the fight against extremism among young people? The point of view of the above-mentioned V. D. Laza is worth to be highlighted. He believes that it is necessary to identify potential suicide 
bombers among people prone to suicidal moods. To do this, he proposes to introduce mandatory testing of high school students, college and university students [2, 45]. Similar socio-psychological surveys and tests on signs of vulnerability and the process of involvement in extremist activity are recommended by other researchers as a method of preventive activity.

M.F. Musaelyan considers the following measures to prevent extremism in general, and in the youth environment in particular:

- instilling the basics of tolerance in young people;

- strengthening state control over the activities of public and religious organizations (charitable organizations, military-patriotic clubs);

- stricter control over the activities of the media and monitoring of the Internet;

- development of a comprehensive youth policy, otherwise, as the author notes, if the state does not take care of youth, others will take care of it - preachers (emissaries, ideologists) of Wahhabism, fascism, nationalism [12,35].

In general, the opinion of those researchers who believe that the education system should "disavow the depravity of radical ideology and practice, form a broad horizon of knowledge" is fair [6,4]. At the same time, attention should be paid to the fact that it is important to avoid formalism, a bureaucratic approach to such activities. For example, L. M. Lutsenko and Yu. V. Lutsenko propose to introduce optional courses on the study of legislation or special disciplines dedicated to teaching the basics of international education of students in educational institutions [3,240]. It is obvious that there is a great danger that during these events it will not be possible to form a deep, not superficial, denial of extremist forms of political activity among the trainees. Similarly, it is necessary to perceive the suggestions of some experts that it is necessary to arrange "meetings with students" concerning the issue of terrorism in educational institutions $[6,3]$.

It is evident that such measures as the creation of voluntary international student squads in universities to maintain public order and prevent conflicts can play a certain role (although their importance should not be exaggerated) [3, 240].

In the conditions of powerful antisocial, extremist propaganda, to which young people are exposed nowadays, it is of great importance to have alternatives for the employment of the younger generation. In this aspect, we consider the recent emergence of such a new institution of civil society as volunteering as a useful alternative for the employment of young people in socially useful activities.

Thus, according to O.I. Kholina: "volunteer activity has its focus on moral education, the revival in the social environment of universal values of culture and morality, without which the state is doomed to destruction" $[15,71]$.

\section{Conclusion}

The development of the Institute of volunteerism is carried out in accordance with the Concept of the Development of Volunteerism in the Russian Federation until 2025, approved by the Government of the Russian Federation in 2018 [10]. According to this document, "volunteerism (volunteering) is an activity in the form of gratuitous performance of works and (or) provision of services in order to solve social problems in such areas as education, health care, culture, social support and social services of the population, physical culture and sports, environmental protection, prevention and elimination of the consequences of emergency situations.

The promotion of the development and dissemination of voluntary (volunteer) activities is one of the priority areas of social and youth policy.

On the basis of a common altruistic goal, volunteering is able to unite people of different ages, faiths, nationalities and social status. In our country, this institution occupies 
an increasingly strong position and is appreciated by the state. In addition to international sporting events, during which volunteers are attracted most massively, the coronavirus epidemic, in turn, required the participation of a large number of volunteers. In this case, the official institutions of government and medicine simply could not cope with the huge flow of patients and the help of volunteers proved invaluable.

In our opinion, when organizing work to identify individuals among the student audience who are subject to the ideology of extremism, it is necessary to remember that modern extremism and terrorism is a fairly organized and well-prepared system. This system is constantly changing, has most of the modern tools. In addition, we must remember that special services play a leading role in prevention issues.

The issues of identifying a recruited or embedded extremist and terrorist at the university should be dealt with by representatives of special services. In this sense, the university should set the task of ensuring effective preventive work among students.

According to the authors of the article, preventive measures can be divided into two levels. The first level implies a set of preventive measures, sometimes this level is also called "operational prevention". In this case, we are talking about the analysis of the symbols used, the behavior of the individuals, their statements, appearance in general. The second level involves the use of a system of measures aimed at the development of positive socio-psychological attitudes, and most often, ideological ones. We believe that this is "deep prevention". The means of implementing the tasks of the second level are education and upbringing. I would like to draw attention to the serious shortcomings that appear when implementing second-level tasks. First of all, this is an authoritarian management style, ignoring the personal interests of young people, which leads, as a rule, to a decrease in social activity.

In general, attention should be paid to the fact that preventive measures to counter the spread of extremist sentiments should be informal, and most importantly - supported by the implementation of national policy to address socio-economic problems, which are the most important factors fueling extremism among some Russian young people.

\section{Acknowledgements}

The reported study was funded by RFBR and EISR, Project number № 21-011-31682.

\section{References}

1. G. M. Gogiberidze, World of press, 51-62 (2017)

2. V. D. Laza, World of press, 39-46 (2017)

3. L. M. Lutsenko, Yu. V. Lutsenko, Lesnoy vestnik, 2, 238-243 (2016)

4. V. L. Nazarov, P. E. Suslonov, Publish House of the Ural University (2018)

5. A. A. Parshina, N. E. Polyanichko, L. A. Guterman, Theory and practice of soc. Develop, 19, 117-121 (2014)

6. Countering the ideology of terrorism in the educational sphere and the youth environment. Study guide for educators (2019)

7. Prevention of extremism and terrorist behavior of young people in the Internet space: traditional and innovative forms. Study guide. Credo (2018)

8. A. M. Aripshev, Historical and socio-educational thought, 9 (5-1), 129-132 (2017). Access mode: https://www.elibrary.ru/download/elibrary_30547986_14122292.pdf

9. Yu. A. Zubok, V. I. Chuprov, Sociological research, 5, 37-47 (2008) 
10. The concept of the volunteerism development in the Russian Federation until 2025: Decree of the Government of the Russian Federation No. 2950-r dated December 27, 2018 (2018). Access mode: http://static.government.ru/media/files/e6LFLgABRP4MyQ8mW7HClCGR8esYBYgq . $\mathrm{pdf}$

11. V. V. Lushchikov, I. R. Stashkevich, Life safety: science, education, practice. Materials of the VII Interregional research to practice conference with international participation: collection of scientific articles, 114-117 (2017). Access mode: https://elibrary.ru/download/elibrary 32521527_46662423.pdf

12. M. F. Musaelyan, Lawyer, 7, 95-99 (2009)

13. The list of public associations and religious organizations for which the court has adopted a decision that has entered into legal force to liquidate or ban activities on the grounds provided for by Federal Law No. 114-FL of 25.07.2002 "On Countering Extremist Activity": Ministry of Justice of the Russian Federation (2021). Access mode: https://minjust.gov.ru/ru/documents/7822

14. S. A. Sergeev, Sociological research, 11, 95-102 (1998)

15. O. I. Kholina, Theory and practice of social development, 8, 71-73 (2011). Access mode: https://www.elibrary.ru/download/elibrary_17749226_23251931.pdf 